\title{
LA CUARTA REVOLUCIÓN INDUSTRIAL 4.0 Y LA PERSPECTIVA DE LA PROFESIÓN DEL CONTADOR PÚBLICO AL FUTURO
}

Mateo Gil Cumaco*, Diego Fernando Urrea López**

\section{Resumen}

El mundo actual se encuentra viviendo un sinnúmero de cambios significativos, que han afectado a la humanidad en todas sus vivencias; una de ellas es la Revolución Industrial 4.0, la cual ha generado cambios relevantes fomentando que los nuevos profesionales contables exploren otros campos de acción y se puedan evidenciar en el mundo digital y tecnológico como una profesión cambiante y perdurable en el tiempo. Por tal motivo, es de gran importancia realizar un ejercicio investigativo del Contador Público y la perspectiva que este tiene frente a este nuevo mundo de la revolución industrial.

* Estudiante, I semestre de Contaduría Pública, Fundación Universitaria del Área Andina. Correo: mgil25@estudiantes.areandina.edu.co

** Docente líder de semillero, Fundación Universitaria del Área Andina. Correo: durrea@ areandina.edu.co 


\section{Introducción}

Los nuevos cambios tecnológicos y digitales que el mundo está viviendo ha hecho que las profesiones tradicionales tengan la necesidad de innovar y desarrollar nuevas perspectivas hacia el futuro. Los estudios al respecto, nos han permitido conocer que algunas profesiones están en peligro de desaparecer. Por tal razón, es necesario reconocer los nuevos cambios que se están aplicando y determinar nuevas proyecciones, en este caso para la profesión contable; en consecuencia, es necesario preguntarnos: ¿cómo impacta la Cuarta Revolución Industrial 4.0 en la profesión del Contador Público?

El ejercicio investigativo que desarrollaremos, tendrá como objetivo principal determinar el grado con que impacta la cuarta revolución industrial en la profesión del Contador Público y de allí partirán unos objetivos específicos que relacionamos a continuación:

$\sqrt{ }$ Caracterizar los riesgos de la profesión contable en la cuarta revolución industrial.

$\sqrt{ }$ Identificar los procesos contables que están sujetos a cambios frente a la cuarta revolución industrial.

$\sqrt{ }$ Establecer los mecanismos de actualización de la profesión contable frente a la cuarta revolución.

Partiendo de estos objetivos, la investigación podrá ser concluida generando resultados óptimos, los cuales permitirán a los profesionales de la Contaduría
Pública y a los diferentes gremios académicos, gubernamentales e instituciones involucradas a generar cambios en la visión y misión de los nuevos profesionales contables.

\section{Metodología}

La investigación será cualitativa y cuantitativa, lo que deduce que existirá un acercamiento a los principales actores del proceso de la profesión de la Contaduría Pública como también a docentes, directivos $y$, por supuesto, los estudiantes de últimos semestres de las universidades de la ciudad de Pereira, queriendo abarcar diferentes escenarios para determinar características propias de una población y la manera de actuar frente a unos cambios tecnológicos y digitales establecidos en un mundo global.

Las técnicas de recolección e información son la encuesta y la entrevista, permitiendo una observación más detallada de los actores que son partícipes de dicha profesión.

\section{Materiales y métodos}

El método a utilizar es inductivo, ya que su objetivo es una manera de argumentación, frente al ordenamiento y análisis de un problema determinado de investigación. En este ejercicio se utilizarán particularidades de la población de estudio, generando así categorías y variables propias de un contexto específico y, con base a ello, se generarán unos resultados comparativos y se podrá llegar a unas conclusiones y recomendaciones de lo específico a lo general de la formación de los nuevos profesionales, desde 
la perspectiva profesional de Contador Público en la Revolución Industrial 4.0

\section{Resultados esperados}

En el desarrollo de este ejercicio investigativo de la profesión contable en la Revolución Industrial 4.0, se espera tener los siguientes resultados al culminar satisfactoriamente la investigación:

$\sqrt{ }$ Caracterización de los riesgos a que está sujeto el Contador Público frente a la cuarta revolución industrial.

$\sqrt{ }$ Reconocimiento de los procesos contables llevados a cabo por el contador acorde con la cuarta revolución industrial.

$\sqrt{ }$ Planteamiento de las estrategias e innovaciones a seguir por parte del Contador Público frente a la cuarta revolución industrial.

Es importante mencionar otros impactos que se pueden generar en la investigación a desarrollar como son:

Impacto económico: cambios de las herramientas tecnológicas frente a los procesos contables en el ejercicio de su profesión ayudarían a las organizaciones a minimizar costos y gastos administrativos.

Impacto social: las nuevas perspectivas de la profesión del Contador Público frente a la cuarta revolución tecnológica y el modo de ver, pensar y hacer los procesos contables ante las nuevas exigencias de la sociedad.

\section{Referencias}

1. Carpio de Cruz, E. L., Cruz Escalante, V. A., \& Martínez García, C. R. (2019). Fortalecimiento de las competencias del profesional en contaduría para ejercer como auditor interno con base en los nuevos requerimientos de la Cuarta Revolución Industrial 4.0 (tesis doctoral). Universidad de El Salvador.

2. Cupitra, V., \& María, A. (2019). La Cuarta Revolución Industrial, una nueva era para la transparencia económica y la profesión contable. https://repository.unimilitar.edu.co/handle/10654/32778

3. Gasca-Hurtado, G. P., \& Machuca-Villegas, L. (2019). Era de la cuarta revolución industrial. RISTI-Revista Ibérica de Sistemas e Tecnologias de Informação, (34), $\mathrm{XI}-\mathrm{XV}$.

4. Romain, M. S. (2019). Transformando organizaciones: liderar el cambio. https:// ebookcentral.proquest.com

5. Saberes emergentes para la cuarta revolución industrial. (2019). https://ebookcentral.proquest.com 